\title{
Finite element head model for the crew injury assessment in a light armoured vehicle
}

\author{
MiCHA£ BURKACKI ${ }^{1}$, WOJCIECH WOLAŃSKI ${ }^{1}$, SŁAWOMIR SUCHOŃ ${ }^{1}$, KAMIL JOSZKO $^{1}$, \\ BOŻENA GZIK-ZROSKA ${ }^{2}$, KAMIL SYBILSKI ${ }^{3}$, MAREK GZIK ${ }^{1}$ \\ ${ }^{1}$ Department of Biomechatronics, Faculty of Biomedical Engineering, Silesian University of Technology, Zabrze, Poland. \\ ${ }^{2}$ Department of Biomaterials and Medical Devices Engineering, Faculty of Biomedical Engineering, \\ Silesian University of Technology, Zabrze, Poland. \\ ${ }^{3}$ Department of Mechanics and Applied Computer Science, Faculty of Mechanical Engineering, \\ Military University of Technology, Warsaw, Poland.
}

\begin{abstract}
Purpose: The aim of this paper was the development of a finite element model of the soldier's head to assess injuries suffered by soldiers during blast under a light armoured vehicle. Methods: The application of a multibody wheeled armoured vehicle model, including the crew and their equipment, aenabled the researchers to analyse the most dangerous scenarios of the head injury. These scenarios have been selected for a detailed analysis using the finite element head model which allowed for the examination of dynamic effects on individual head structures. In this paper, the authors described stages of the development of the anatomical finite element head model. Results: The results of the simulations made it possible to assess parameters determining the head injury of the soldier during the IED explosion. The developed model allows the determination of the parameters of stress, strain and pressure acting on the structures of the human head. Conclusion: In future studies, the model will be used to carry out simulations which will improve the construction of the headgear in order to minimize the possibility of the head injury.
\end{abstract}

Key words: head model, HIC, head injury, safety assessment

\section{Introduction}

Safety assessment of the human head is one of the dominant topics of modern biomechanics. The most commonly used Hybrid III dummy provides information regarding injury criteria based on dynamic parameters. Hybrid III is widely used in experimental and model studies. A multibody model of a Light Armoured Vehicle (LAV) Gzik et al. [4] was used to determine a number of factors that may affect the safety of soldiers during the IED (Improvised Explosive Device) blast under the vehicle. Selected simulation scenarios focused on ergonomic factors regarding seat belts, seat angle settings and equipment.
The analysis shows that the use of 4-point belts ensures the highest level of safety compared to other analysed systems. The angle of 100 degrees of the seat backrest obtains the lowest criteria for the head and spinal injury. During the simulation, it was noticed that the equipment can cause serious injuries when coming into contact with a soldier during an explosion, which indicates the need to fix all loose objects in the vehicle.

Available criteria for cervical spinal injury are sufficient to assess the probability of injury. In turn, the head injury criterion (HIC) is determined only on the basis of linear acceleration recorded by the acceleration sensor in the dummy's head. However, it does not give information about what happens within the structures

\footnotetext{
* Corresponding author: Michał Burkacki, Department of Biomechatronics, Faculty of Biomedical Engineering, Silesian University of Technology, ul. Roosevelta 40, room 116, 41-800 Zabrze, Poland. E-mail: michal.burkacki@polsl.pl

Received: February 3rd, 2020

Accepted for publication: April 28th, 2020
} 


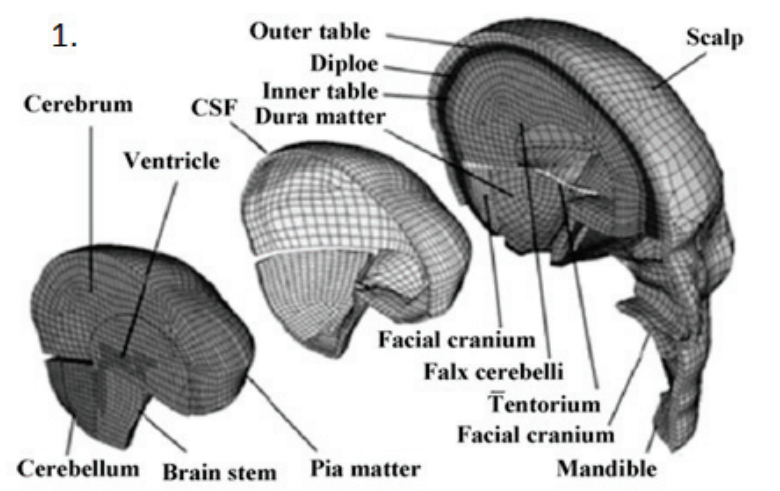

2.
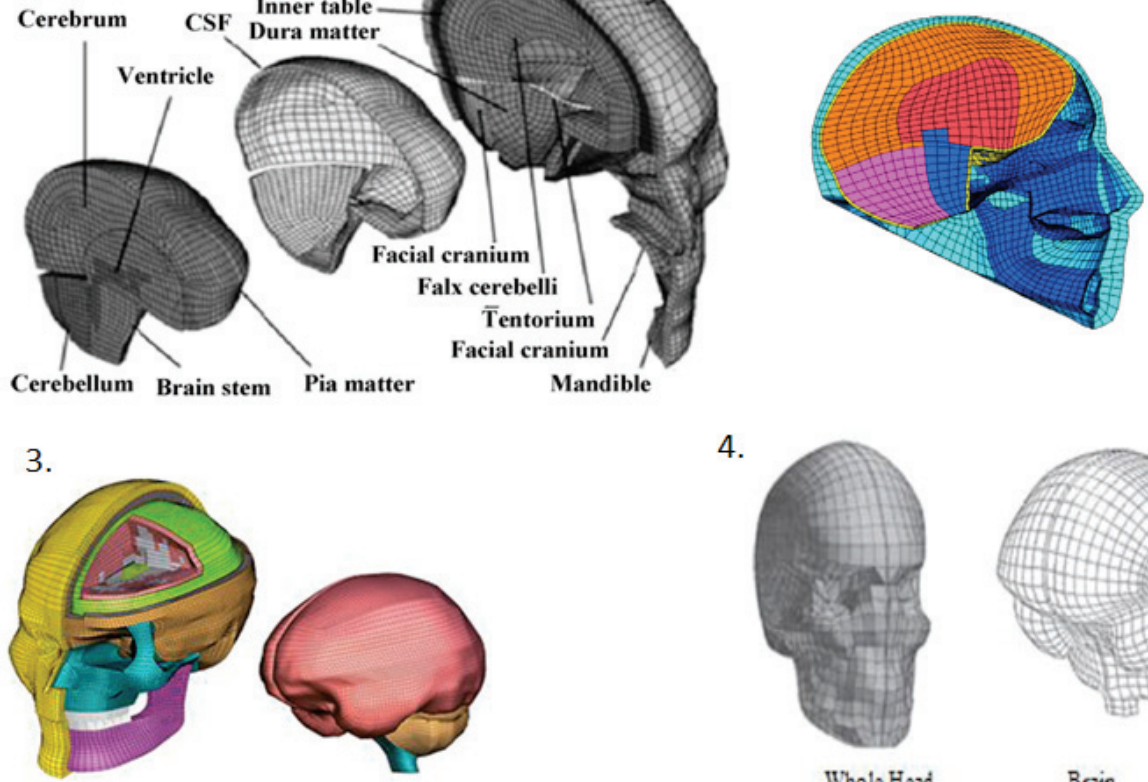

4.
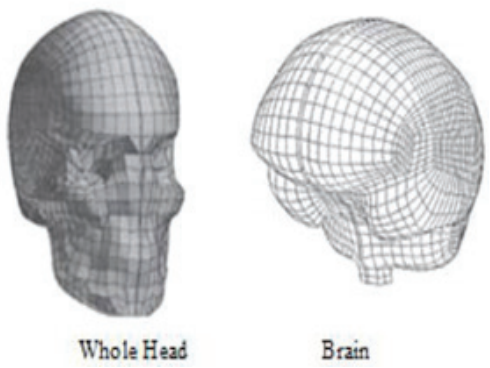

Fig. 1. Finite element models of human head
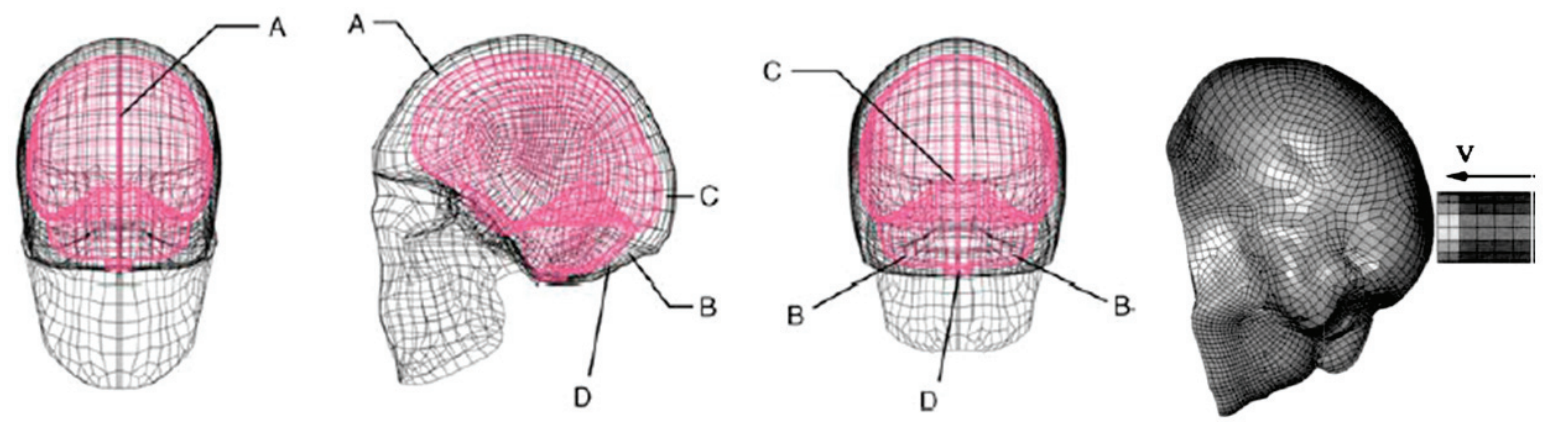

Fig. 2. From the left: Location of pressure sensors during Nahum test [21], impactor location [22]

of the human head during a head injury. Therefore, many authors have developed human head models to determine phenomena occurring during the head impact. Most often, the head is modelled using the finite element method (FEM), which allows for the analysis of individual tissue layers and their material characteristics. FEM head models are used in many fields of science. Head and spine models are created to analyse safety in car accidents [7], [16]. Many head models are created to improve medical procedures [10]. Authors have also investigated helmets for head ballistic protection [6]. The simplest head model is the EEVC WG17 impactor model [3]. It was developed to investigate injuries caused by a head impact on the car bonnet. Advanced models more or less reflect the anatomical structure of the human head. The following models: Yang [22], Yao [23], Ward [19], Zhang [24], Mao [12], Horgan [5], Kang [8], Takhounts [17] were mainly developed for the purpose of safety assessment of car accidents. Most authors took into account the main layers of the brain with different material properties (Fig. 1).

Material properties of human head meninges were obtained in cadaver experimental tests. Authors used linear elastic material models as well as viscoelastic. Presented models were mainly verified in experimental tests (Nahum [15]). As part of these tests, the corpse was hit on the head with a steel impactor, whose mass was $5.59 \mathrm{~kg}$ (Fig. 2). In the skull there were 4 pressure sensors located in the following places: a - frontal zone, $\mathrm{b}$ - occipital zone, c - parietal zone, $\mathrm{d}$ - fossa zone (marked in Fig. 2). They are located in a thin layer of the brain called the subarachnoid, between the pia and dura mater. The contact force and head acceleration were also determined from the experiment with the impactor speed of $9.94 \mathrm{~m} / \mathrm{s}$. 


\section{Materials and methods}

This paper presents model simulations including the analysis of factors that may affect soldier's head safety in a LAV vehicle. To assess the safety of the human head, the authors used a hybrid approach of both multibody and FEM method in LS-DYNA software. The research involved the following stages: development of a finite element human head model, model verification, head injury assessment using a multibody vehicle model including the crew and the FEM head model (Fig. 3). Presented finite element model of human head was created for commercial project „Afgan” (NCBiR grant No. DOBR-BIO4/ 022/13149/2013). The model geometry is based on CT and MR imaging of 75 th percentile adult. Therefore, such percentile was mainly involved in incidents involving IED in a light armoured vehicle from war in Afghanistan and Iraq for Polish soldiers. Authors decided to create own model with full control of geometry which also affected final mesh quality. This approach made it possible to obtain a high-quality finite element mesh. Presented model has also been parameterized so that it can be scaled for future purposes to 25 th and 50th or 95th percentile. The hybrid approach of multibody and FE modelling of injury in LAV is also a new approach to this subject and one of the main differences between other published research. Further, boundary conditions involved in presented simulation are different from others, because they contain very high accelerations effected on soldiers.

\subsection{Development of the finite element human head model}

For the analysis of dynamic effects on the head during explosions, a detailed geometry of structures reflecting the anatomical structure of bones and soft tissues should be taken into account. As part of the research, head structures were segmented based on the image data obtained from $\mathrm{CT}$ and MR imaging of an

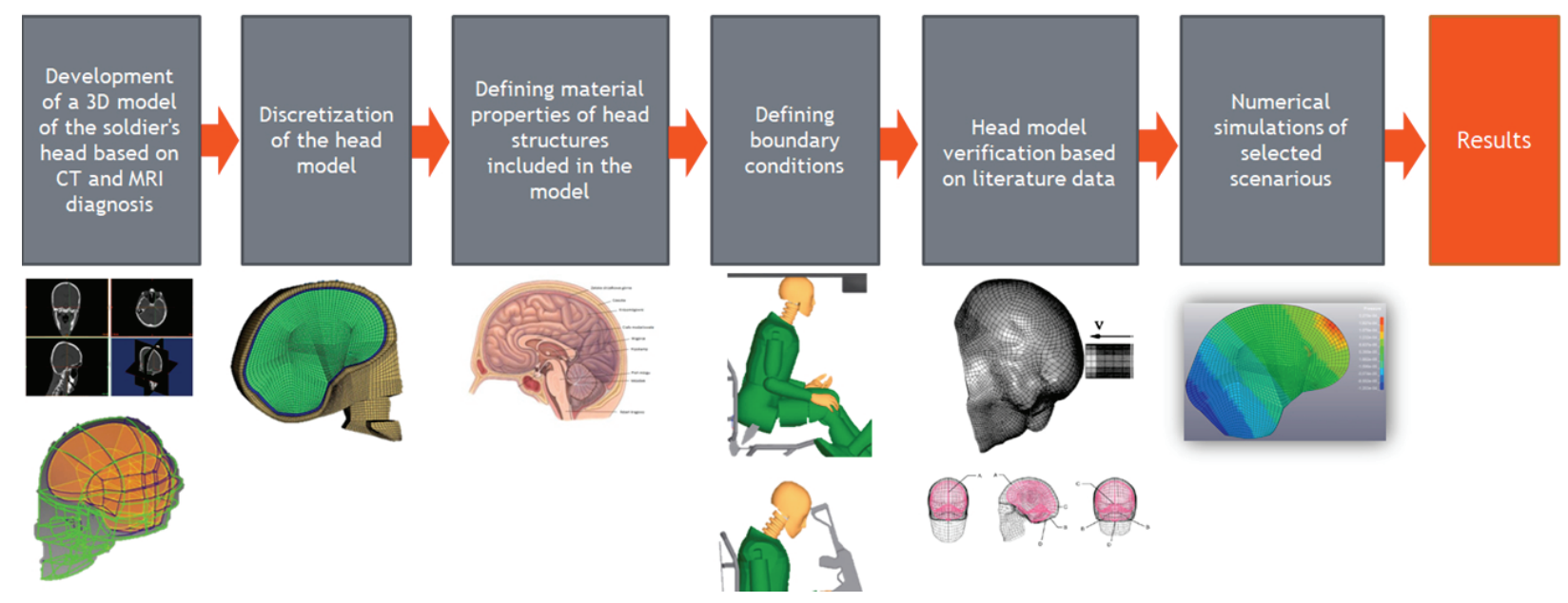

Fig. 3. Stages of safety assessment

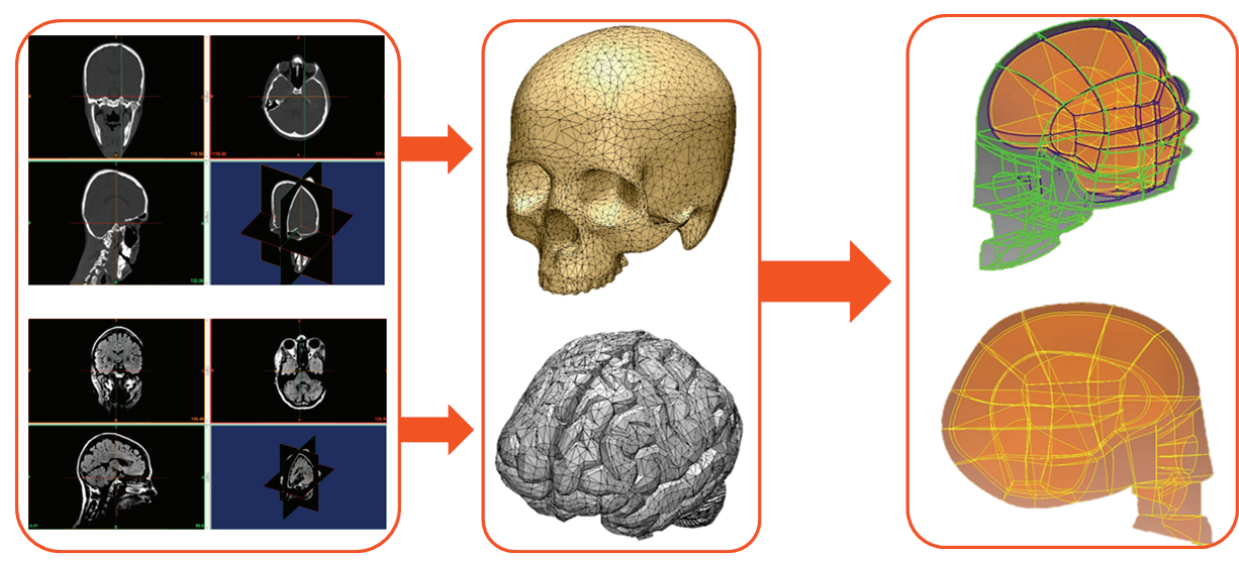

Fig. 4. Process of model development 
adult 75 th percentile male. Mimics software was used for the segmentation process in which bone structures were segmented from Dicom CT images. Soft tissues (brain structure) were segmented based on Dicom MR images. The exported model from Mimics software in the STL format has been loaded into the CAD environment (Autodesk Inventor) in which modifications were made by tracing individual structures using spline curves (Fig. 4).
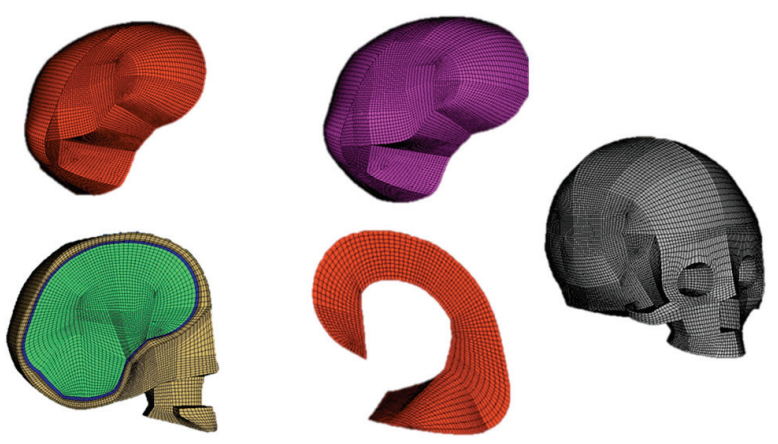

Fig. 5. Developed mesh for the human head model
Afterwards, the finished surface model of the head structures was exported to the ICEM CFD software to obtain a high-quality hexahedral mesh. Hexahedral elements were obtained using the solid mapping function. At the final stage of the discretization process, the head model was obtained consisting of 297536 hexahedral elements and 35670 shell elements (Fig. 5). Warpage of elements was a maximum of 35.2 for the whole model and 17.6 for the brain model. The aspect ratio of the whole model was a maximum of 7.15 and 5.69 for the brain model. Maximum length parameter was 2.46 and minimum -0.49 - for the whole model and max 2.46 and min 0.58 for the brain model. The Jacobian parameter for the whole model was above 0.7 for the whole model (including the brain). The full head model consisted of 11 parts: cortical and cancellous bone of the skull, brain (divided into the cerebrum, cerebellum, brainstem). The cerebrospinal fluid have been meshed with hexahedral elements, whereas falx cerebri, tentorium cerebelli, arachnoid, dura mater were meshed with shell elements.

Table 1. Material properties of head structures with LS-DYNA material parameters

\begin{tabular}{|c|c|c|c|c|c|c|c|}
\hline $\begin{array}{c}\text { Anatomical } \\
\text { part of the head }\end{array}$ & $\begin{array}{l}\text { Density } \\
{\left[\mathrm{kg} / \mathrm{m}^{3}\right]}\end{array}$ & $\begin{array}{c}\text { Young } \\
\text { modulus } \\
{[\mathrm{Gpa}]}\end{array}$ & $\begin{array}{l}\text { Poisson's } \\
\text { ratio }\end{array}$ & $\begin{array}{c}\text { Bulk } \\
\text { modulus } \\
{[\mathrm{Gpa}]}\end{array}$ & $\begin{array}{c}\text { Short-term } \\
\text { shear } \\
\text { modulus } \\
{[\mathrm{kPa}]}\end{array}$ & $\begin{array}{l}\text { Long-term } \\
\text { shear } \\
\text { modulus } \\
{[\mathrm{kPa}]}\end{array}$ & $\begin{array}{c}\text { Decay } \\
\text { constant } \\
{\left[\mathrm{s}^{-1}\right]}\end{array}$ \\
\hline Dura mater & 1100 & 0.0315 & 0.35 & & & & \\
\hline Arachnoid & 1100 & 0.012 & 0.35 & & & & \\
\hline Pia mater & 1100 & 0.0125 & 0.35 & & & & \\
\hline Falx cerebri & 1100 & 0.0125 & 0.35 & & & & \\
\hline Tentorium cerebelli & 1100 & 0.0315 & 0.3 & & & & \\
\hline Cortical bone & 2000 & 10 & 0.22 & & & & \\
\hline Cancellous bone & 1300 & 0.6 & 0.24 & & & & \\
\hline Cerebrum & 1060 & & & 2.19 & 6.0 & 1.2 & 80 \\
\hline Cerebellum & 1060 & & & 2.19 & 6.0 & 1.2 & 80 \\
\hline Brain steam & 1060 & & & 2.19 & 6.0 & 1.2 & 80 \\
\hline Cerebrospinal fluid & 1040 & & & 2.19 & 0.5 & 0.1 & 80 \\
\hline
\end{tabular}

Table 2. LS-DYNA parameters

\begin{tabular}{|l|l|c|c|}
\hline \multicolumn{1}{|c|}{ Part } & \multicolumn{1}{c|}{ Material type } & Element Type & Layer thickness \\
\hline Dura mater & *MAT_ELASTIC & SHELL & $2 \mathrm{~mm}$ \\
\hline Arachnoid & *MAT_ELASTIC & SHELL & $1 \mathrm{~mm}$ \\
\hline Pia mater & *MAT_ELASTIC & SHELL & $1 \mathrm{~mm}$ \\
\hline Falx cerebri & *MAT_ELASTIC & SHELL & $2 \mathrm{~mm}$ \\
\hline Tentorium cerebelli & *MAT_ELASTIC & SHELL & $2 \mathrm{~mm}$ \\
\hline Cortical bone & *MAT_ELASTIC & SOLID & - \\
\hline Cancellous bone & *MAT_VISCOELASTIC & SHELL & $1 \mathrm{~mm}$ \\
\hline Cerebrum & *MAT_VISCOELASTIC & SOLID & - \\
\hline Cerebellum & *MAT_VISCOELASTIC & SOLID & - \\
\hline Brain steam & *MAT_VISCOELASTIC & SOLID & - \\
\hline Cerebrospinal fluid & *MAT_VISCOELASTIC & SOLID & - \\
\hline
\end{tabular}


Material properties of the brain were established on the basis of literature data from cadaver tests Bilston et al. [1] and Chatelin et al. [2]. The material properties of the craniofacial bone were obtained from the results of McElhaney et al. [13], Wood [20] and Melvin et al. [14] (Table 1).

The LS-DYNA software was used to simulate the head model using the finite element method. The properties of the linear-elastic material were specified in the * MAT_ELASTIC (001) card. On the other hand, the properties of the viscoelastic material were determined in the * MAT_VISCOELASTIC (006) card. Model parameters are presented in Table 2.

Interaction of subsequent layers has been achieved through following assumptions. The dura mater was a layer attached to the inner surface of skull. Common nodes were adopted for cortical and cancellous bone elements. Common nodes were also defined for shell and all brain elements. The inferior of dura mater is a layer called arachnoid. Elements of pia mater are attached to the surface of the brain. The pia mater is the membrane attached to the surface of the brain tissue. Solid elements representing cerebrospinal fluid (CSF) are outside of the brain. The arachnoid is imitated by the outer surface of the CSF. Material properties of CSF were assumed for the bulk modulus of water and a very low shear modulus. The sliding boundary algorithm was defined between CSF and pia mater. Sliding interfaces were implemented with a friction coefficient of 0.2 . The course of the model simulation was controlled by hourglass using the function *CONTROL_HOURGLASS with the parameters $\mathrm{IHQ}=5$ and $\mathrm{QH}=0.1$.

\subsection{Model verification}

Verification of the head model was carried out on the basis of the pressure curves obtained from the experiment carried out by Nahum [15] described in the introduction. In the model, the contact force at the skull nodes was defined (at the place of contact of the skull with the impactor) by the course of force presented in Fig. 6. This approach was used by many authors (Kang et al. [8], Horgan et al. [5], Zhou et al. [25], Kleiven et al. [9]).

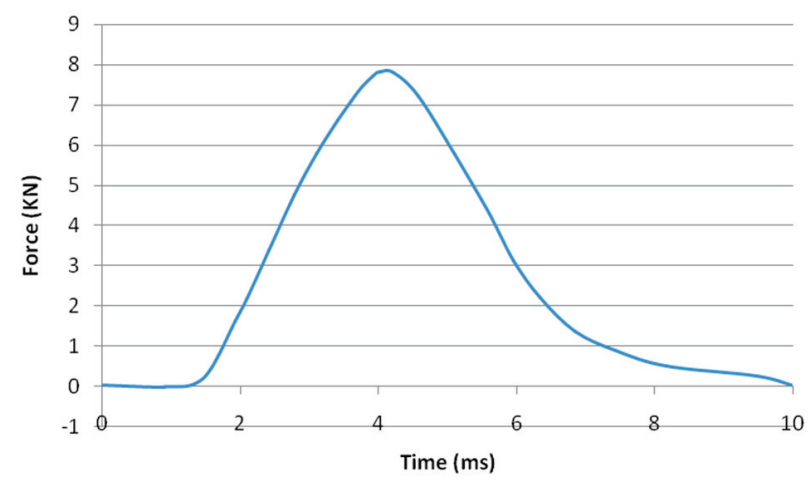

Fig. 6. The contact force between the impactor and the skull

The pressure distribution of the brain model obtained from the simulation was compared with the pressure values of the model by Mao et al. [12] (Fig. 7). After obtaining an acceptable correlation of pressure distribution in the brain model, the pressure courses for the frontal (Fig. 8), occipital (Fig. 9), parietal (Fig. 10) and fossa (Fig. 11) zones were also compared. The location of the points from which the pressure course was taken was chosen in the same way as in the Yan, Pangestu [21] model (Fig. 2). The variance in the pressure waveforms was small and was considered acceptable, which could be due to simplifications adopted in the model. The percentage difference in maximum pressure was the largest in the fossa zone of the brain $(6 \%)$, while the smallest difference was obtained for the frontal zone $(0.5 \%)$. The results obtained in the verification process were considered to suffice because of the obtaining of qualitatively similar pressure courses in individual brain zones.
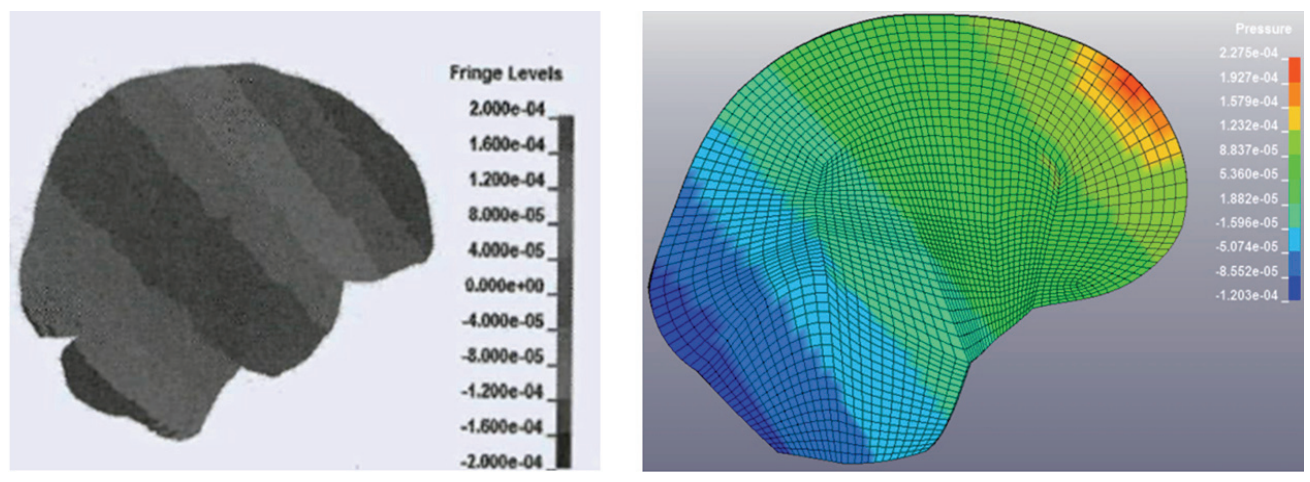

Fig. 7. Comparison of pressure distribution [Pa] of the brain model for $t=5 \mathrm{~ms}$ [64]: on the left - is model of [12], on the right - authors' model 


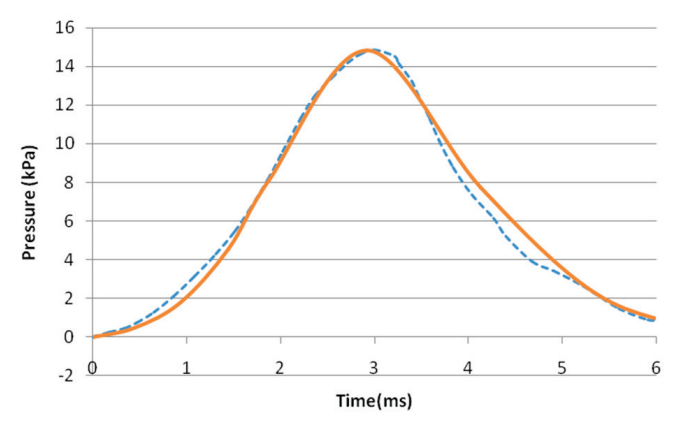

Fig. 8. Pressure in frontal zone

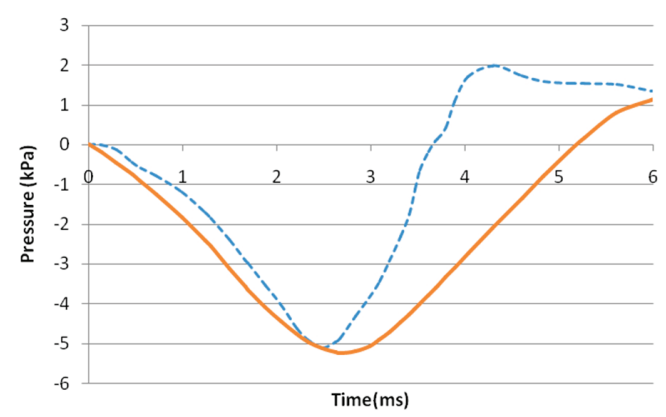

Fig. 9. Pressure in occipital zone

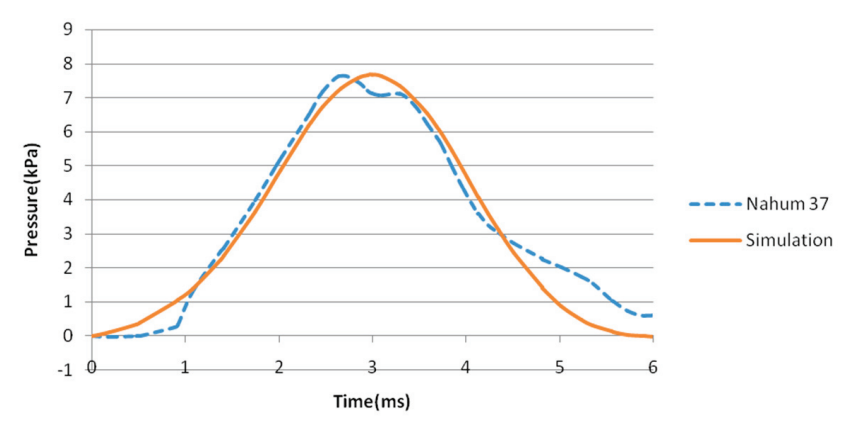

Fig. 10. Pressure in parietal zone

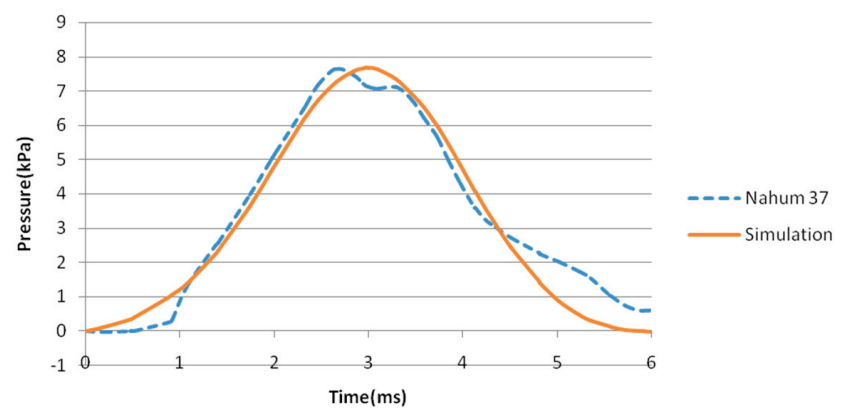

Fig. 11. Pressure in fossa zone

\subsection{Head injury assessment}

The presented head model allowed for a detailed analysis of factors affecting head injury. To assess the safety of human head in a LAV vehicle, the authors used a hybrid approach of both multibody and FEM method. From previous studies by Gzik et al. [4], including the multibody vehicle model with crew members, the most dangerous scenarios have been selected which could cause head injuries. The most high-risk incidents for the soldier's head were associated with the head hitting the vehicle ceiling and the equipmentweapon impact. These scenarios were used to simulate impact with the use of the developed Finite Element Head Model in the LS-DYNA software. From the numerical simulations carried out in the MADYMO software (Fig. 12), five events were selected for analysis. Scenarios included vehicle acceleration of $180 \mathrm{~g}, 250 \mathrm{~g}$ and $300 \mathrm{~g}$. These loads were selected in „Afgan" project as the most common ones during IED explosion basing on data collected from IED incidents

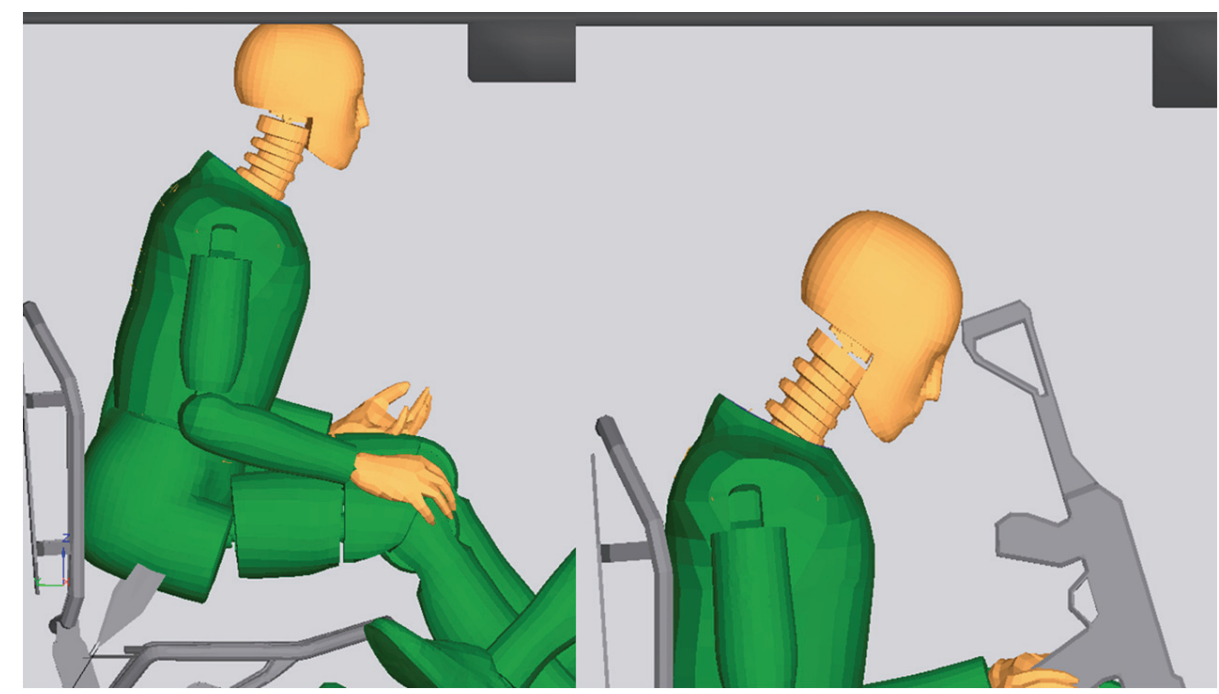

Fig. 12. The moment of dummy's head hitting the vehicle ceiling / the moment of rifle hitting the soldier's head in MADYMO software 
from war in Afghanistan and Iraq (for Polish soldiers). Simulations were carried without a military helmet to check the correctness of the model and the injury criteria obtained by other authors. The impact of weapons was also investigated without a helmet, because rifles were coming into contact with the forehead.

1. Event $\mathrm{A}$ - head impact against the vehicle ceiling for a dummy fastened in a 2-point seat belt system, with vehicle acceleration of $180 \mathrm{~g}$.

2. Event B - head impact against the vehicle ceiling for a dummy fastened in a 2-point seat belt system, with vehicle acceleration of $250 \mathrm{~g}$.

3. Event $\mathrm{C}$ - head impact against the vehicle ceiling for a dummy fastened in a 2-point seat belt system, with vehicle acceleration of $300 \mathrm{~g}$.

4. Event D - impact of the Beryl rifle on the dummy's head.

5. Event E - impact of the heavy PKM rifle on the dummy's head.
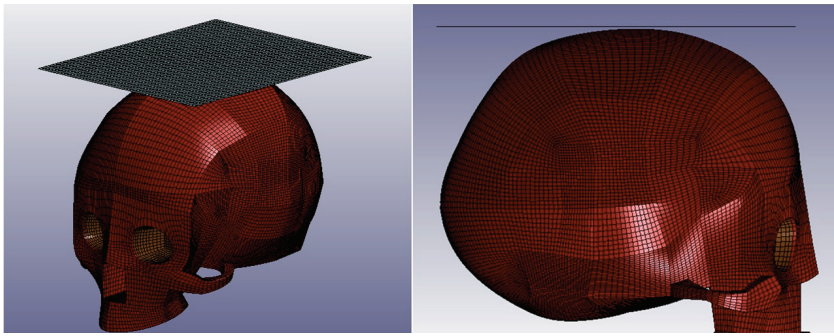

Fig. 13. Head model with a plate model

The head impact simulation on the vehicle body was mapped in the LS-DYNA program by introducing a steel plate $\left(\right.$ density $\left.=7860 \mathrm{~kg} / \mathrm{m}^{3}\right)$ to the model (Fig. 13), which was presented in the form of 2500 rigid shell elements defined in the * MAT_RIGID (020 card).

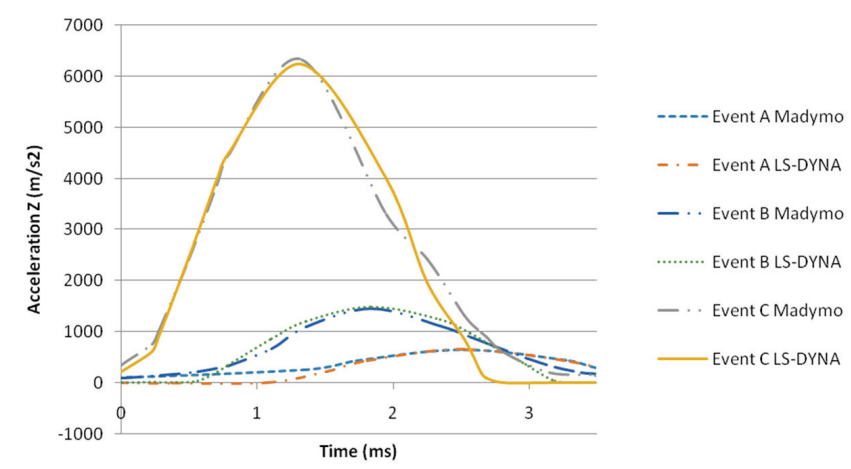

Fig. 14. Comparison of head acceleration waveforms for head impact on the ceiling
The boundary conditions (initial speed) in the head model simulation were determined on the basis of the results obtained from the simulation of the Hybrid III dummy. The obtained values of the head model acceleration were consistent with the obtained accelerations for the dummy's head. The highest acceleration value was obtained in the direction of the $Z$ axis. In Fig. 14, the acceleration waveforms for individual simulation events are shown.

The geometry of the weapon in the form of rigid elements defined in the * MAT_RIGID (020) card was added to simulate the rifle impact (Fig. 15).

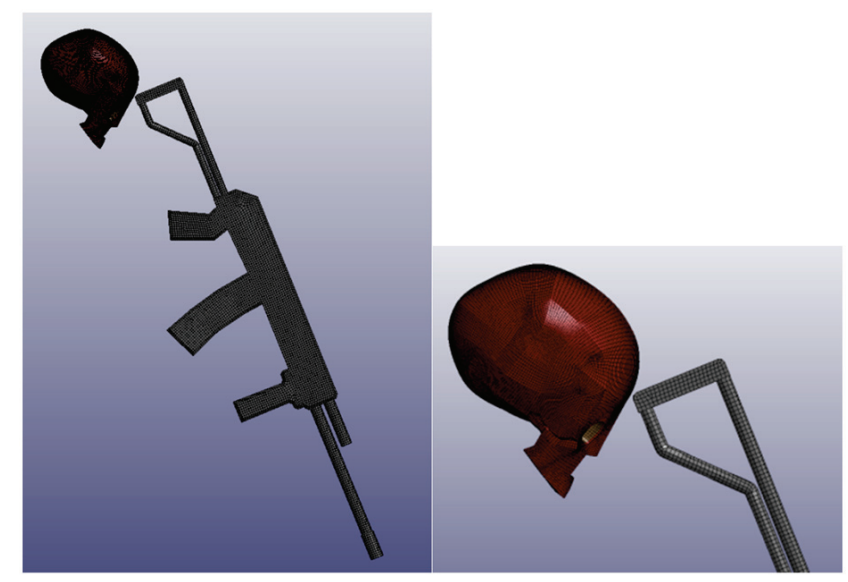

Fig. 15. Head model with a weapon model

The boundary conditions (initial speed of the weapon) in the head model simulation were determined based on the results obtained from the simulation in the MADYMO software. The initial velocity for the Beryl weapon was $7 \mathrm{~m} / \mathrm{s}$ and its weight was $3.9 \mathrm{~kg}$. The initial velocity for the heavy PKM rifle was $11 \mathrm{~m} / \mathrm{s}$ and its weight was $20 \mathrm{~kg}$. The obtained values of the resultant acceleration of the head model were consistent with the obtained accelerations for the dummy's head (Fig. 16).

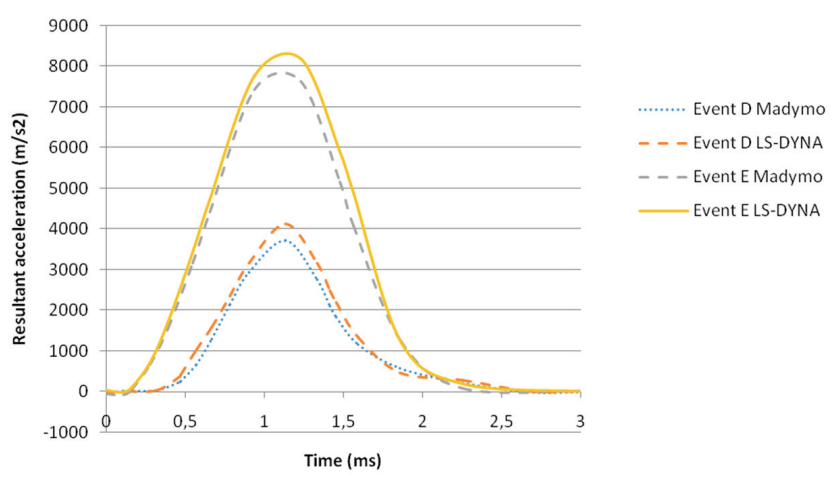

Fig. 16. Comparison of head acceleration waveforms during head impact 


\section{Results}

Developed FEM model of human head allowed for the analysis of a number of parameters indicating the possibility of head injury as a result of hitting the head against the ceiling of the vehicle and impact of weapons. To compare the simulation results, the following parameters were taken into account: maximum brain pressure in the impact zone (Figs. 17 and 18), maximum brain pressure on the other side of the impact, maximum principal strain of the cortical skull layer (Fig. 19), maximum principal stress of the cancellous bone, maximum brain stress, maximum brain Tresca (maximum shear stress). The obtained results were compared to Mao's [12], Ward's [19] and Zhang's [8] criteria (Table 3). The exceeding of injury criteria have been marked in red. Injury criteria of 0.42 for maximum principal strain of the cortical skull layer

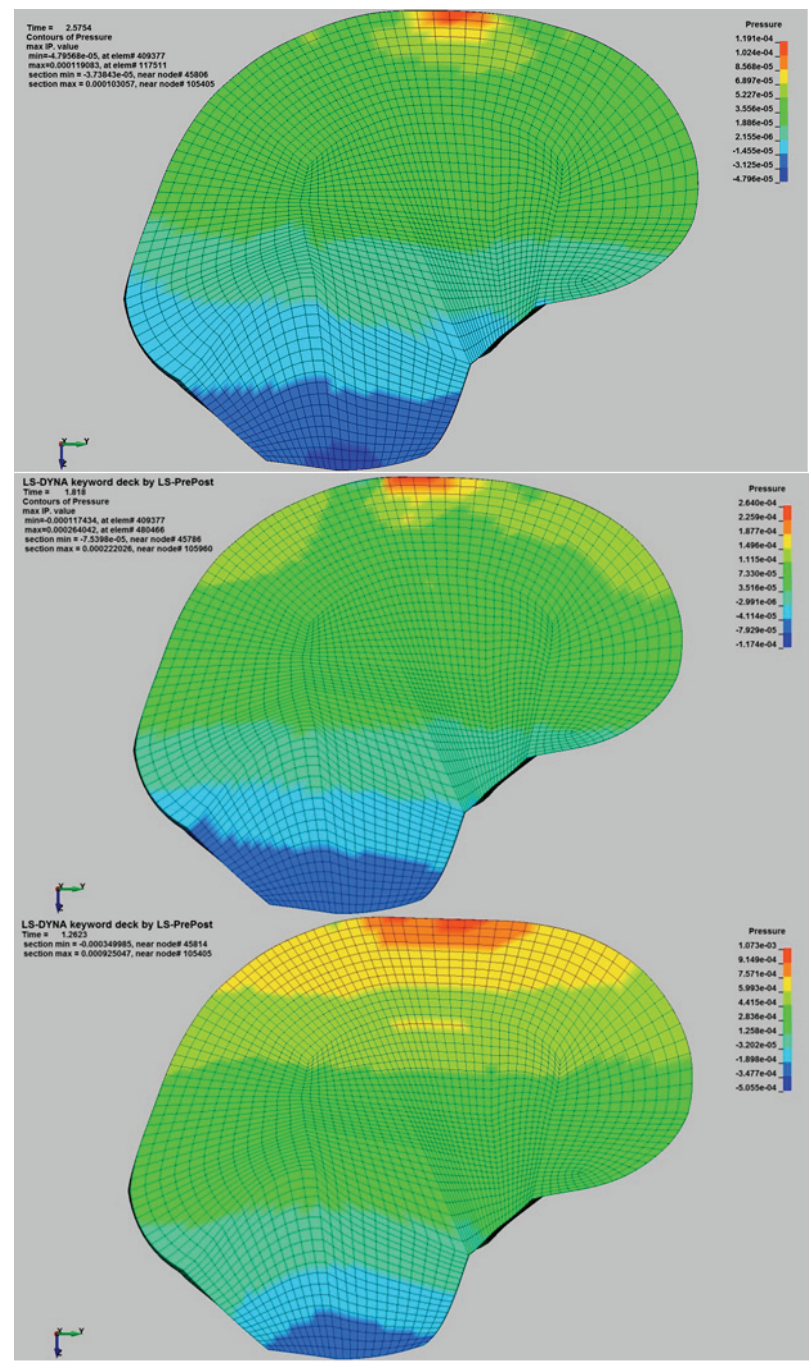

Fig. 17. Pressure values (GPa) of the brain obtained in events (from top) a, b, c (a cross-sectional view in the sagittal plane)
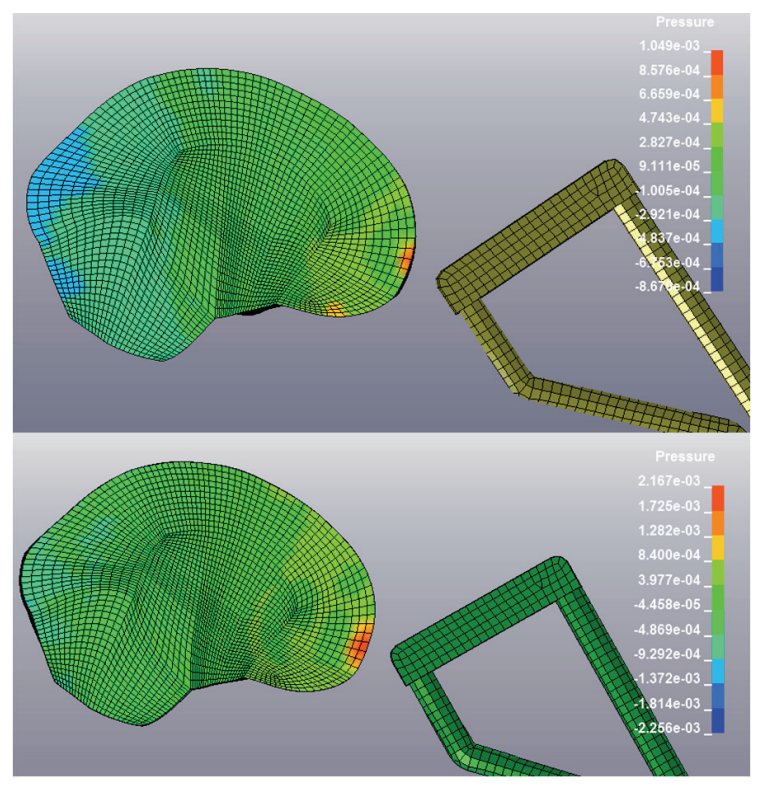

Fig. 18. Pressure values (GPa) of the brain obtained in events (from top) d, e (a cross-sectional view in the sagittal plane)

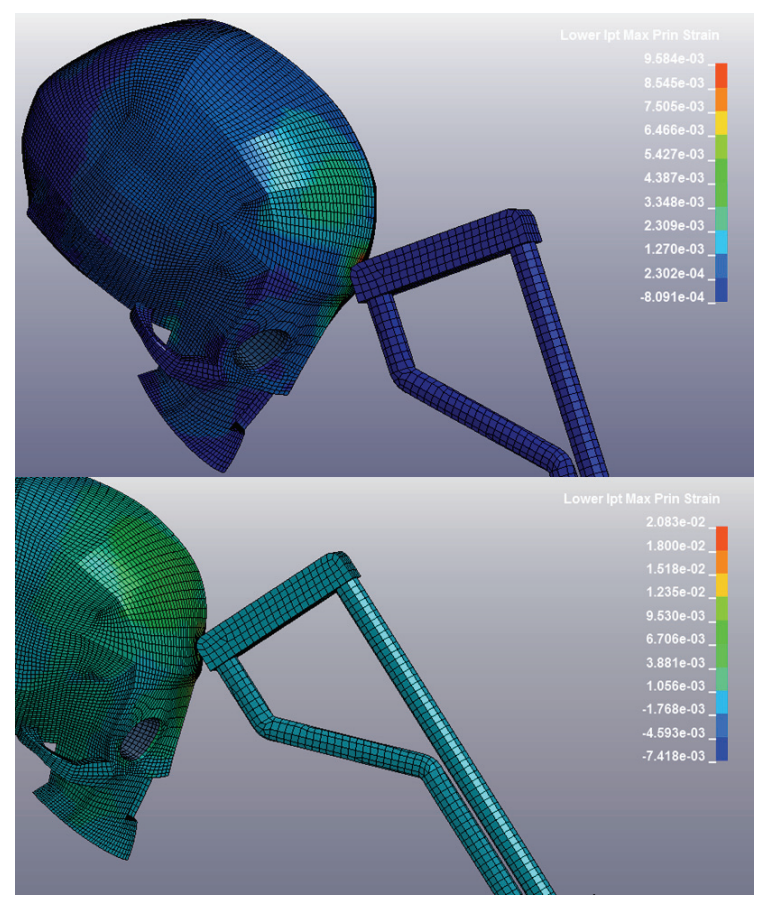

Fig. 19. Maximum principal strain of the cortical skull layer obtained in events (from top) d, e

were exceeded in events B, C, D, E. Injury criteria of $20 \mathrm{MPa}$ for maximum principal stress of the skull cancellous bone were exceeded in events C, D, E. Injury criteria of $200 \mathrm{kPa}$ for maximum brain pressure in the impact zone were exceeded for events B, C, D, E. Injury criteria of $-186 \mathrm{kPa}$ for maximum brain pressure on the other side of the impact $(\mathrm{kPa})$ were exceeded in events C, D, E as well as injury criteria of $14.8 \mathrm{kPa}$ for maximum stress in the brain and injury 
Table 3. Maximum values of stress, strain and pressure in FE head model for individual events

\begin{tabular}{|l|c|c|c|c|c|c|}
\hline \multicolumn{1}{|c|}{ Event } & $\begin{array}{c}\text { Maximum } \\
\text { principal strain } \\
\text { of the cortical } \\
\text { skull layer [\%] }\end{array}$ & $\begin{array}{c}\text { Maximum } \\
\text { principal stress } \\
\text { of the skull } \\
\text { cancellous bone } \\
{[\mathrm{MPa}]}\end{array}$ & $\begin{array}{c}\text { Maximum } \\
\text { brain pressure } \\
\text { in the impact zone } \\
{[\mathrm{kPa}]}\end{array}$ & $\begin{array}{c}\text { Maximum } \\
\text { brain pressure } \\
\text { on the other side } \\
\text { of the impact } \\
{[\mathrm{kPa}]}\end{array}$ & $\begin{array}{c}\text { Maximum } \\
\text { stress in the } \\
\text { brain } \\
{[\mathrm{kPa}]}\end{array}$ & $\begin{array}{c}\text { Maximum tresca } \\
\text { (maximum shear } \\
\text { stress) in brain } \\
{[\mathrm{kPa}]}\end{array}$ \\
\hline \multicolumn{1}{|c|}{ Injury criteria } & $0.42[12]$ & $20[12]$ & $200[19]$ & $-186[19]$ & $14.8[12]$ & $7.8[24]$ \\
\hline $\begin{array}{l}2-\text { point seatbelt } \\
180 \text { g (A) }\end{array}$ & 0.39 & 1.68 & 119 & -43 & 3.94 & 2.16 \\
\hline $\begin{array}{l}\text { 2-point seatbelt } \\
\text { 250 g (B) }\end{array}$ & 0.73 & 10.8 & 264 & -117 & 8,33 & 4.7 \\
\hline $\begin{array}{l}\text { 2-point seatbelt } \\
300 \text { g (C) }\end{array}$ & 1.8 & 31.7 & 1073 & -505 & 32 & 18 \\
\hline $\begin{array}{l}\text { Weapon Beryl } \\
\text { Impact 7 m/s (D) }\end{array}$ & 0.98 & 22.3 & 1049 & -867 & 15.6 & 8.27 \\
\hline $\begin{array}{l}\text { Weapon PKM } \\
\text { impact } 11 \mathrm{~m} / \mathrm{s} \text { (E) }\end{array}$ & 2.08 & 66.6 & 2167 & -2256 & 41.1 & 24.5 \\
\hline
\end{tabular}

criteria of $7.8 \mathrm{kPa}$ for maximum brain Tresca. In the case of a light rifle (Beryl, event D), the stresses, strains and pressures obtained are at least twice as low as those of a heavy rifle (PKM, event E).

\section{Discussion}

The developed head model took into account the main anatomical structures of the head with their mechanical properties that could affect the obtained simulation results. It was important to use viscoelastic material for the brain layers to obtain correct results. The head structure segmentation based on magnetic resonance imaging and computed tomography images allowed accurate brain geometry to be reflected in the CAD software.

The process of model discretization was very laborious and time-consuming, as a result of which a highquality finite element mesh was obtained, which translated into minimal calculation errors. The proposed modelling process can be used to create other anatomical models of human body parts. Often, to discretize models, tools are used to automatically generate a tetrahedral mesh, regardless of errors that may result from the limitation of used elements. This creates a real need for the development of software that would allow for obtaining a hexahedral finite element mesh based on medical images.

The verification of the head model made it possible to compare the value of pressure acting on the brain when hitting a steel impactor. A satisfactory correlation of results was obtained both between the maximum pressure value and its time course. The hybrid approach of multibody modelling toggether with the use of the finite element method allowed for the analysis of many factors in a relatively short time. Presented model also behaves stable at high accelerations within $300 \mathrm{~g}$.

By comparing the results of the simulations performed with the results of other authors' criteria, it was possible to determine the conditions in which both skull and brain injury could occur. When using 2-point belts (Event A), in which the head was hit at the maximum acceleration of $180 \mathrm{~g}$, there was no fracture of the skull bone or brain injury despite contact with the vehicle's ceiling. The simulation results obtained in event B (2-point belt, acceleration $250 \mathrm{~g}$ ) indicated a fracture of the cortical skull layer with a $50 \%$ probability of AIS3+ injury which could cause a severe head injury, concussion with loss of consciousness from 1 to 6 hours, brain hematoma. A HIC criterion of 485 for this event indicated a $10 \%$ probability of AIS3+ head injury, while head pressure of $264 \mathrm{kPa}$ indicated a $30 \%$ probability of AIS3+ injury. The results clearly indicate the need for the analysis of not only acceleration but also pressure on the brain. In the simulation for Event C (2-point belt, $300 \mathrm{~g}$ acceleration), the head impact against the vehicle ceiling resulted in a serious injury to the cortical and cancellous bone fractures, as well as to a serious brain injury at AIS3+ level. The impact of Beryl (event D) and PKM (event E) rifles also caused serious injuries to the cortical and cancellous bone as well as resulted in a high probability of brain injury at AIS3+ level. Therefore, it can be concluded that hitting both light and heavy rifles can lead to serious head injuries. This confirms the recommendations on the use of mounts of weapons and any other loose parts in a military vehicle, as they can turn into deadly objects during an explosion. Simulations were carried out without a mili- 
tary helmet to check the correctness of the model and the injury criteria obtained by other authors. The developed model can also be used to assess the construction of helmets because it allows for a thorough analysis of factors affecting head injuries. In the future research, it is planned to use the model to perform simulations, the results of which can be used to improve the design of helmets to minimize the possibility of head injuries. The head protection structures developed by using the finite element head model can be designed to minimize pressure on the human brain. In the future research, the authors are planning to include Fluid-Structure Interaction modelling which will be able to reflect the effects of a blast wave impact on the human brain [17]. There is also a need for the development of models that will enable the prediction of micro traumatic brain injuries [11].

\section{Conclusions}

The head injury criterion HIC is determined only on the basis of the linear acceleration value, which is recorded in the centre of the head mass. It does not provide information about what happens to the brain tissue during the collision of the head with the surroundings in the vehicle. The above-described process of creating the model is a time-consuming and laborious process, however, it allows discretization of complex geometries reflecting the anatomy of the human head. The author's model of the human head allowed for the analysis of the effects of dynamic interactions on individual head structures. The developed model allows for determining stress as well as deformation and pressure parameters acting on the human head structures. The presented model is validated by Nahum experiment, therefore authors plan to carry out additional validation in future research. The model also behaves stable at high accelerations within $300 \mathrm{~g}$. The authors are aware that a large number of brain models was developed lately, but a lot of them weren't validated, as mentioned in Yang and King? Also many authors use tetrahedral mesh with viscoelastic material properties which leads to incorrect results. Most of them are not available for commercial purposes, therefore, the authors decided to create own model with full control of geometry, which also affected final mesh quality. This approach made it possible to obtain a high-quality finite element mesh. Presented model has also been parameterized so that it can be scaled for future purposes. Further, the hybrid approach of multibody and FE modelling of injury in LAV is also a new approach to this subject and of the main difference between other published research.

The results of the simulations carried out using developed human head model allowed for the assessment of parameters that determine the injury of the soldier's head during an IED blast that would enable the development of guidelines to improve safety. Although computer simulations are becoming more and more accurate, the most valuable results are provided by experiments or obtained from real-world accidents. Therefore, in order to improve the safety of soldiers during an explosion under a military vehicle, it seems important to introduce measuring systems that can record accelerations acting on the vehicle and soldiers during the explosion. These data should be saved in "black boxes" and collected after each incident. The accident register created would contain a detailed description of the soldiers' injuries and associated parameters. This would allow for a thorough analysis of injuries occurring in the soldier's body, whereas the results obtained would allow improving the available safety solutions for soldiers.

\section{Acknowledgements}

The presented research was carried out as part of the NCBiR grant No. DOBR-BIO4 / 022/13149/2013 of 20/12/2013. We would like to thank the company CESARZ Tłumacze Przysięgli S.C. for verifying the grammar of this article.

\section{Conflict of interest}

The authors declare that the article content was composed in the absence of any commercial or financial relationships that could be construed as a potential conflict of interest.

\section{References}

[1] Bilston, Brain Tissue Mechanical Properties, Stud. Mechanobiol. Tissue Eng. Biomater., 2011, 3, 11-24.

[2] Chatelin S., Constantinesco A., Willinger R., Fifty Years of Brain Tissue Mechanical Testing: From In Vitro to In Vivo Investigations, Biorheology, 2010, 47 (5-6), 255-276.

[3] Frank T., Kurz A., Martin P., Sollner M., Development and Validation of Numerical Pedestrian Impactor Models, 4th European LS-DYNA Users Conference.

[4] Gzik M., Wolański W., Gzik-Zroska B., Joszko K., BURKACKI M., SUCHOŃ S., Analysis of Various Factors Impact on Safety of Armored Vehicle Crew During an IED Explosion, Recent Developments and Achievements in Biocybernetics and Biomedical Engineering, DOI: 10.1007/978-3-319-66905-2 26.

[5] HoRgan T.J., GILCHRIST M.D., The creation of three-dimensional finite element models for simulating head impact biomechanics, I. J. Crash, 2003, Vol. 8, No. 4. 
[6] Jamroziak K., Polak S., StęPień R., Bocian M., Kosobudzki M, Possibilities of ballistic protection of the head in the light of the traumatic criterion on the example of the helmet wz. wz. 93, 2016, TKI (in Polish).

[7] Joszko K., Wolański W., BuRKacki M., Suchoń S., ZIELONKA K., MuSZYŃSKI A., GZIK M., Biomechanical analysis of injuries of rally driver with head supporting device, Acta Bioeng. Biomech., 2016, 18 (4), DOI: 10.5277/ ABB-00633-2016-03.

[8] Kang H.S., Willinger R., Diaw B.M., Chinn B.. Validation of a $3 D$ anatomic human head model and replication of head impact in motorcycle accident by finite element modeling, Proceeding of 41th Stapp Car Crash Conference, 1997, 329-338.

[9] KLeIven S., Holst H., Consequences of head size following trauma to the human head, Journal of Biomechanics, 2002, 35 (2), 156-160.

[10] KaWlewsKa E., Wolański W., Larysz D., GZIK-Zroska B., Joszko K., GzIK M., Gruszczynska K., Advances in Intelligent Systems and Computing, 2017, 526, DOI: 10.1007/ 978-3-319-47154-9 16.

[11] Hazay M., Dénes D., BojtÁr I., The Probability of Traumatic Brain Injuries Based on Tissue-level Reliability Analysis, Acta Bioeng. Biomech., 2019, 21(1).

[12] Mao H., Zhang L., Genthikatti J., Makwaana G., JANDIR S., YANG K., Development of a Finite Element Human Head Model Partially Validated With Thirty Five Experimental Cases, Journal of Biomechanical Engineering, 2013, 135.

[13] McElhaney J.H., Fogle J.L., Melvin J.W., Haynes R.R., Roberts V.L., Alem N.M., Mechanical Properties on Cranial Bone, J. Biomech., 1970, 3 (5), 495-511.

[14] Melvin J.W., RobBins. D.H., RoberTs V.L., The Mechanical Properties of the Diploë Layer in the Human Skull in Compression, Dev. Mech., 1969, 5, 811-818.

[15] NAHUM A.M., SMith R., WARD C.C., Intracranial pressure dynamics during head impact, Proceedings of the 21st Stapp Car Crash Conference, 1977, SAE, Paper No. 770922.

[16] Sybilski K., MaŁachOwsKi J., Sensitivity study on seat belt system key factors in terms of disabled driver behavior during frontal crash, Acta Bioeng. Biomech., 2019, 21 (4), DOI: 10.5277/ABB-01421-2019-02.

[17] Tan X.G., PrZekwas A.J., Gupta R.K., Computational modeling of blast wave interaction with a human body and assessment of traumatic brain injury, Shock Waves, 2017, 27 (6), 1-16.

[18] Takhounts E., Eppinger R., Campbell J., Tannous R., Power E., SHOOK L., On the Development of the SIMon Finite Element Head Model, Stapp Car Crash Journal, 2003, 47, 107-33.

[19] WARD C.C., ChAN M., NAHUM A.M.. Intracranial pressure - a brain injury criterion, Proceeding of 24th Stapp Car Crash Conference, 1980, SAE 801304.

[20] Wood J.L., Dynamic Response of Human Cranial Bone, J. Biomech., 1971, 4 (1), 1-12.

[21] Yan W., Dwiputra Pangestu O., A modified human head model for the study of impact head injury, Computer Methods in Biomechanics and Biomedical Engineering, 2010, 1049-1057.

[22] YANG J., Investigation of Brain Trauma Biomechanics in Vehicle Traffic Accidents Using Human Body Computational Models, Computational Biomechanics for Medicine, 2011, DOI: 10.1007/978-1-4419-9619-0_2

[23] Yao J., YAng J., Отte D., Investigation of head injuries by reconstructions of real-world vehicle-versus-adult-pedestrian accidents, Safety Science, 2008, 46 (7).

[24] Zhang L., Hardy W., OmOri K., YANG K.H., King A.I., Recent advances in brain injury research: a new model and new experimental data, Bioengineering Center, 2001.

[25] Zhou C., Khali T., King A., A new model comparing impact response of the homogenous and inhomogeneous human brain, Proceedings of the 39th Stapp Car Crash Conference, 1995, 952714, 121-137. 